\title{
JUDICIALIZAÇ̃̃O DOS CONFLITOS SOCIAIS: REFLEXÕES SOBRE A NECESSIDADE DE SOLUÇÕES DIALÓGICAS NO ESTADO DEMOCRÁTICO DE DIREITO BRASILEIRO
}

\author{
Max Emiliano da Silva Sena ${ }^{1}$ \\ Carlos Victor Muzzi Filho ${ }^{2}$
}

\section{RESUMO}

Este artigo objetiva analisar a judicialização dos conflitos sociais, propondo reflexões sobre como se obter soluções consensuais, sem a necessidade de recorrer ao Poder Judiciário. Se a previsão de direitos sociais nos textos constitucionais traduz uma importante conquista, o excesso de litígios judiciais cristaliza os conflitos e compromete a efetiva realização desses direitos. Conciliação, mediação, arbitragem, termo de juste de conduta e comissões de conciliação prévia são alguns meios alternativos de soluções extrajudiciais para conflitos relativos aos direitos sociais no Estado Democrático de Direito brasileiro, que podem ser mais eficientes do que a tradicional composição pela via judicial.

Palavras-chave: Judicialização; Conflitos sociais; Estado Democrático de Direito brasileiro; Solução dialógica; Meios alternativos.

\section{JUDICIALIZATION OF SOCIAL CONFLICTS: REFLECTIONS ON THE NEED FOR DIALOGUE SOLUTIONS IN THE DEMOCRATIC STATE OF BRAZILIAN LAW}

\begin{abstract}
This article aims to analyze the judicialization of social conflicts, proposing reflections on how to obtain consensual solutions, without the need to resort to the Judiciary. If the prediction of social rights in constitutional texts represents an important conquest, the excess of judicial litigation crystallizes the conflicts and compromises the effective realization of these rights. Conciliation, mediation, arbitration, justification of conduct and prior conciliation commissions are some alternative means of out-of-court settlement of disputes concerning social rights in the Democratic State of brazilian Law, which may be more efficient than traditional judicial composition.
\end{abstract}

Keywords: Judicialization; Social Conflicts; Democratic State brazilian of Law; Dialogical Solution; Alternative methods.

\section{INTRODUÇÃO}

\footnotetext{
${ }^{1}$ Mestrando em Direito pela Universidade FUMEC. Procurador do Trabalho, do Ministério Público do Trabalho (MPT). Professor de Direito Constitucional e de Direitos Humanos na Universidade Vale do Rio Doce (UNIVALE). Especialista em Direito Público pela Faculdade de Direito do Vale do Rio Doce (FADIVALE) e em Direitos Humanos e Trabalho pela Escola Superior do Ministério Público da União (ESMPU)

${ }^{2}$ Mestre e Doutor em Direito Tributário pela Faculdade de Direito da Universidade Federal de Minas Gerais (UFMG). Professor da graduação e do mestrado em Direito da Universidade FUMEC. Advogado e Procurador do Estado/MG.
} 
A previsão de direitos sociais nos textos constitucionais representou importante conquista histórica, passando-se da proteção contra os abusos dos governantes para a promoção de melhorias das condições de vida em sociedade, em busca da ampliação do respeito à dignidade da pessoa humana.

A realidade brasileira, vale assentar, está a exigir, ainda, a efetiva implementação daqueles direitos fundamentais de segunda dimensão, quais sejam, os direitos sociais, reputados estratégicos para se proporcionar a concretização da igualdade material, e positivados especialmente no artigo $6^{\circ}$ da Constituição da República de 1988 (BRASIL, 1988).

No entanto, a implementação efetiva desses direitos sociais gerou, ao longo do tempo, certa inflação legislativa, para que, por meio de leis e atos normativos, se tornassem efetivamente exigíveis. Mas essa positivação mais concreta, que se seguiu às primeiras conquistas, não se mostrou completamente eficiente, desaguando, em momento posterior, no Poder Judiciário, buscando-se, pela via da judicialização, a concretização desses direitos sociais, em claro reflexo da falência dos mecanismos baseados no diálogo para a solução das dissensões que, naturalmente, afloram nas relações travadas entre os atores sociais.

O excesso de demanda judicial, além de oneroso e contraproducente em muitos casos, acaba por cristalizar ainda mais as tensões sociais, sem, realmente, resolver essas tensões e, claro, sem pacificar as relações sociais.

Nesse estágio de desenvolvimento do Estado Democrático de Direito, são imperiosas a criação e a viabilização de mecanismos que também permitam aos próprios interessados a construção de soluções para os conflitos, a partir de releitura do princípio de acesso à justiça, que deve apontar para o direito à solução adequada, eficiente e eficaz para os desentendimentos, não se limitando ao simples direito a um provimento emanado dos órgãos do Poder Judiciário, muitas vezes demorado e já inócuo.

A reflexão que se propõe reside na análise de como a mediação, a conciliação, a arbitragem, o termo de ajuste de conduta e as comissões de conciliação prévia podem representar mecanismos para a construção de soluções dialógicas, sem a necessidade do ajuizamento de ações perante o Judiciário, e que têm como pretensão proporcionar o alcance da pacificação social.

Com a identificação de formas consensuais de solução de conflito objetiva-se refletir acerca da teoria e da aplicação dos métodos complementares de solução de conflitos, 
notadamente aqueles que sejam pautados por soluções construídas a partir de diálogos travados entre as partes interessadas, de caráter não impositivo, e que convirjam para o fortalecimento da cultura da paz social, sem a intervenção do Poder Judiciário.

Empregou-se, metodologicamente, o método de abordagem indutivo e a pesquisa dogmático-jurídica de natureza bibliográfica, por meio da consulta de obras e legislação.

\section{A CONQUISTA DE DIREITOS CONTRA E POR MEIO DO ESTADO}

Na égide do Estado absolutista quase não havia restrição jurídica à conduta dos governantes, que detinham o poder soberano, ilimitado e incontrastável, embora, vale observar, a previsão de direitos não fosse desconhecida no antigo regime (DOUZINAS, 2009). A frase atribuída ao Rei Luís XIV, que governou a França nos séculos XVII e XVIII, retrata bem esse período, no qual o Estado se confundia com a pessoa do soberano. Ao dizer “o estado sou eu” (RÓNAI, 1986, p. 326), Luís XIV apresentava-se como a personificação do Estado e detentor de poder de mando ilimitado sobre os súditos, no âmbito do território sob seu governo.

Embora seja possível garimpar elementos de direitos humanos na Antiguidade, não se contava nesse período com nenhum sistema efetivo de proteção do indivíduo contra o poder dos governantes. Sidney Guerra, a propósito, observa que:

\footnotetext{
No que tange à denominada proto-história dos direitos humanos, como sustenta Comparato, teve início na Baixa Idade Média, mais exatamente na passagem do século XII ao século XIII. Não se trata ainda de uma afirmação de direitos inerentes à própria condição humana, mas sim o início do movimento para a instituição de limites do poder dos governantes, o que representou uma grande novidade histórica. Foi o primeiro passo em direção ao acolhimento generalizado da ideia de que havia direitos comuns a todos os indivíduos, qualquer que fosse o estamento social (clero, nobreza ou povo) (GUERRA, 2015, p. 52).
}

Do estudo da gestação dos direitos humanos sob a perspectiva de suas dimensões ressai, na observação de Pedro Lenza, que "os direitos humanos de $1^{\text {a }}$ dimensão marcam a passagem de um Estado autoritário para um Estado de Direito e, nesse contexto, o respeito às liberdades individuais, em uma verdadeira perspectiva de absenteísmo estatal" (LENZA, 2014, p. 1056). A imposição de limites à atuação estatal decorreu do movimento liberalburguês, no século XVIII, como forma de proteger as liberdades públicas e os direitos civis e políticos, diante dos mandos e desmandos dos soberanos totalitários. 
A edição de alguns documentos marca esse período de proteção do indivíduo contra o Estado, podendo-se citar: a Magna Carta de 1215, assinada pelo rei "João Sem Terra", a Paz de Westfália (1648), o Habeas Corpus Act, de 1679, o Bill of Rights, de 1688, a Declaração da Independência dos Estados Unidos, de 1776, e a Declaração Francesa dos Direitos do Homem e do Cidadão, de 1789 (LENZA, 2014).

Não obstante a teoria kelseniana de que haveria identidade entre Estado e Direito, uma vez que ambos constituiriam uma mesma ordem de coerção (CHEVALLIER, 2013), certo é que no Estado de Direito o poder dos governantes é restrito pelas normas por eles mesmos editadas, com o objetivo de proteção dos direitos do homem. Portanto, a ideia de Estado e Direito encontra-se atrelada à garantia dos direitos individuais contra o Estado. Jacques Chevallier, nesse tom, destaca que:

\begin{abstract}
O primeiro aspecto da limitação do poder reside na referência aos direitos do homem. O Estado de Direito implica, com efeito, certa concepção das relações entre o indivíduo e o Estado, que sustenta todo o edifício jurídico: não somente o poder do Estado encontra os seus limites nos direitos fundamentais reconhecidos aos indivíduos, o que cria, assim, a possibilidade de uma "oposição ao poder fundada no direito" (C. Lefort), mas também ela tem por finalidade, por justificação última, a garantia desses direitos; no final das contas, o Estado de Direito se apoia na afirmação da primazia do indivíduo na organização social e política, o que acarreta ao mesmo tempo a instrumentalização do Estado, cujo objetivo é servir às liberdades e à subjetivização do direito (L. Ferry, A. Renaut, Philosophie politique, III Des droits de l'homme à l'idée républicaine, PUF, 1985), que dota cada um de um estatuto, que lhe atribui um poder de exigibilidade e lhe confere uma capacidade de ação. (CHEVALLIER, 2013, p. 46)
\end{abstract}

Sem embargo da grande importância representada pela previsão dos direitos contra o Estado, a saber, mecanismos de salvaguarda contra os abusos estatais, tem-se que, no palco histórico de péssimas condições de trabalho, durante a Revolução Industrial europeia, a partir do século XIX, eclodem movimentos de reivindicação de melhorias nas condições de trabalho e de previsão de normas de assistência aos necessitados. Impôs-se a constatação de que os direitos de proteção contra a prática de arbitrariedades estatais não foram capazes de alterar a realidade fática de pobreza e de vulnerabilidade de considerável parte da população. A igualdade meramente formal não refletiu na conquista da igualdade material. Para Lenza:

O início do século XX é marcado pela Primeira Grande Guerra e pela fixação de direitos sociais. Essa perspectiva de evidenciação dos direitos sociais, culturais, econômicos, bem como dos direitos coletivos, ou de coletividade, correspondendo aos direitos de igualdade (substancial, real e material, e não meramente formal), mostra-se marcante em alguns documentos, destacando-se: - Constituição do México, de 1917; - Constituição de Weimar, de 1919, na Alemanha, conhecida 
como a Constituição da primeira república alemã; - Tratado de Versalhes, 1919 (OIT); - no Brasil, a Constituição de 1934 [...] (LENZA, 2014, p. 1057)

Esses direitos, chamados de segunda geração ou dimensão (BONAVIDES, 2010) exigem do Estado atuação mais ativa, em comparação com os chamados direitos de primeira geração (ou dimensão), mediante prestações mais concretas ou materiais (BONAVIDES, 2010), de modo a, efetiva e positivamente, ofertar melhores condições materiais em favor das pessoas, como garantia do chamado mínimo existencial. Poder-se-ia dizer, de modo esquemático, que enquanto os direitos de primeira dimensão são contra o Estado, os de segunda dimensão são concretizados por meio do Estado.

\section{A SACRALIZAÇÃO DO DIREITO E O MOVIMENTO DE JURIDICIZAÇÃO DAS CONDUTAS}

Se num primeiro momento o Direito foi utilizado como mecanismo legitimação de governos ilegítimos (CHEVALLIER, 2013), mediante a institucionalização de um Estado de Direito meramente formal, constata-se que em etapas seguintes ele passa não somente a limitar os governantes, mas também a pautar e condicionar as ações estatais, de molde a proteger e promover os direitos fundamentais, por meio de direitos previstos em documentos de hierarquia superior, notadamente nas Constituições.

A par disso, ocorre verdadeira sacralização do Direito, como instrumento de concretização do Estado de Direito numa perspectiva substancial e, por consequência, proliferam-se os textos normativos, na medida em que se passou a acreditar que somente por meio deles seria possível a proteção adequada nas várias relações travadas no meio social.

A propósito do tema, Jacques Chevallier explica que:

O Estado de Direito implica uma confiança absoluta depositada no direito, a crença nas virtudes da dogmática jurídica para atingir os objetivos que se lhe atribuiu, em fazer prevalecer os valores aos quais se está vinculado: é pela transformação em direitos subjetivos que serão preservadas as liberdades individuais; é pela proclamação da soberania nacional que será garantido o princípio da democrático; é pela afirmação da liberdade do comércio e da indústria que será protegida a sociedade civil contra dos riscos de ingerência estatal. O Estado de Direito se assentar, assim, sobre o fetichismo da regra: a norma jurídica tende a ser tomada como a própria realidade, capaz de fazer advir o que enuncia; e a passagem pela forma jurídica vem constituir a sua garantia suprema. [...] A teoria do Estado de Direito é, dessa forma, apenas o prolongamento e a coroação de uma longa tradição. De fato, a sua essência é o normativismo (W. Leisner, 1974): ele tende também a um "perfeccionismo normativo" constante e a uma ampliação incessante do campo da juridicidade; todas as relações sociais devem ser submetidas ao direito, codificadas 
em termos jurídicos. Se o Estado de Direito quer ser perfeito, ele deve estar em toda a parte: "a legalidade é uma noção absoluta senão totalitária: quem não está por ela está contra ela”. O Estado de Direito tende, por conseguinte, à juridicização integral da ordem social. (CHEVALLIER, 2013, p. 52-53)

A proliferação exacerbada dos textos normativos, como corolário da sacralização do direito, acaba por gerar efeito indesejado, qual seja, a ampliação da pressão jurídica, com destaque para a explosão do contencioso, por meio da judicialização de conflitos de natureza individual ou coletiva. Nesse cenário, o Poder Judiciário é chamado a decidir sobre questões muitas vezes simplórias, que outrora eram passíveis de solução por outros mecanismos de conciliação, fora do âmbito judicial. É novamente Jacques Chavallier quem destaca que:

\begin{abstract}
Os conflitos que se desenvolvem no seio das instituições, tais como a escola, são mais e mais frequentemente levados perante a Justiça; as relações entres os operadores econômicos são cada vez mais enquadradas por decisões da Justiça (M.A. FRISON-ROCHE, 2005): quanto à judiciarização dos conflitos do trabalho, questão particularmente sensível na França, ela é subproduto da fragilidade dos sindicatos que os conduzem a contar com a intervenção do juiz mais do que com a sua capacidade de mobilização. $O$ próprio poder político tende a transferir para o juiz o incômodo de decidir determinadas questões sensíveis (assem se viu na França em 1989 com a questão do "lenço islâmico", antes que o legislador se reapossasse do problema em 2004). Essa ampliação de poderia dá testemunho da fragilidade de outras instituições, como a família, que era tradicionalmente encarregada de regular os comportamentos e do déficit de legitimidade da própria instância política, que parece incapaz de arbitrar os diversos interesses sociais em conflito. (CHEVALLIER, 2009, p. 132)
\end{abstract}

Também Boaventura de Sousa Santos correlaciona a "consolidação do Estadoprovidência", com a "expansão dos direitos sociais e, através deles, a integração das classes trabalhadoras nos circuitos de consumo anteriormente fora do seu alcance", com o que ele denomina de "explosão da litigiosidade à qual a administração da justiça dificilmente poderia dar resposta" (SANTOS, 1986, p. 16).

Assim, embora sejam compreensíveis os motivos que muitas vezes levam à judicialização dos conflitos, haja vista que o Poder Judiciário traz consigo a "garantia de um processo equitativo, inclusive quando se demanda contra os poderosos" (CHEVALLIER, 2009, p. 133), tem-se que o "recurso à Justiça também produz alguns efeitos perversos, ao cristalizar os conflitos: o legalismo conflitual comportará um conjunto de custos econômicos, institucionais, humanos. [...] indo até a denúncia do espectro do governo dos juízes" (CHEVALLIER, 2009, p. 133-134). 
Apesar disso, essas críticas são inaptas a obstar um processo que tem se revelado irreversível, dadas as garantias proporcionadas pelo sistema judicial, notadamente um julgamento imparcial e com caráter de definitividade.

Essa necessidade de normatização das condutas e a demanda recorrente ao Poder Judiciário para dirimir os conflitos surgidos, embora legítimo e necessário em muitos casos, põe em evidência a incapacidade dos próprios atores sociais de resolverem autonomamente suas questões, cada vez mais complexas. A esse respeito, é mais uma vez de Jacques Chevallier a afirmação de que:

\begin{abstract}
A juridicização crescente do tecido social se traduz no fato de que o direito é, a partir de então, chamado a reger as relações humanas que se submetiam anteriormente a modos de regulação extrajurídicos ou fundados na confiança. Mas é também a demonstração de uma ampliação da complexidade da organização social, que impõe uma regulação mais acurada. (CHEVALLIER, 2009, p. 134)
\end{abstract}

Objetivando verificar, no caso do Brasil, os impactos desse movimento de juridicização das condutas sociais e de recorrente demanda ao Poder Judiciário, foram consultados dados divulgados pelo Conselho Nacional de Justiça e que constam do "Relatório Justiça em Números 2016", em sua página da rede mundial de computadores (internet), relativo ao ano-base de 2015 (BRASIL, 2016).

Para fazer face às crescentes demandas da sociedade, de acordo com dados de 2015, o Poder Judiciário brasileiro encontra-se estruturado em 15.773 unidades judiciárias de primeiro grau, assim distribuídas: 10.156 varas estaduais, 1.570 varas do trabalho, 976 varas federais, 3.039 zonas eleitorais, 13 auditorias militares estaduais e 19 auditorias militares da União (BRASIL, 2016, p. 31).

Em todo o Poder Judiciário, conta-se com força de trabalho total correspondente a 451.497 servidores, sendo 17.338 magistrados (3,8\%), 278.515 servidores efetivos, cedidos, requisitados e comissionados $(61,7 \%)$ e 155.644 de força de trabalho auxiliar (34,5\%), que abrange os terceirizados, estagiários, juízes leigos, conciliadores e colaboradores voluntários (BRASIL, 2016, p. 37).

No que tange a novos casos recebidos pelo Poder Judiciário em 2015, tem-se o total de 27.278.629 casos, assim distribuídos: a) Justiça Estadual: 18.911.657; b) Justiça do Trabalho: 4.058.477; c) Justiça Federal: 3.662.876; d) Tribunais Superiores: 538.313; e) Justiça Eleitoral: 103.087; f) Justiça Militar Estadual: 4.219; Auditoria Militar da União: 1.658 (BRASIL, 2016, p. 43). 
Já no que tange aos casos ainda pendentes, em 2015, tem-se o total de 64.936.309 processos, distribuído assim: a) Justiça Estadual: 59.030.179; b) Justiça Federal: 9.073.741; c) Justiça do Trabalho: 5.049.890; d) Justiça Eleitoral: 80.617; e) Tribunais Superiores: 696.795; f) Justiça Militar Estadual: 3.093; g) Auditoria Militar da União: 1.994 (BRASIL, 2016, p. 43).

Em 2015, as despesas só com recursos humanos no Poder Judiciário brasileiro corresponderam a $\mathrm{R} \$ 70.665 .944 .284,00$, equivalente a $89,2 \%$ do seu orçamento (BRASIL, 2016, p. 36).

Nota-se, importante assentar, que esse sistema não tem se mostrado eficiente, registrando Walid Machado Botelho Arabi que esse "cenário de esgotamento da capacidade estatal de distribuir justiça e aplicar o direito" tem afetado "diretamente a confiança depositada pela população no Poder Judiciário, como aponta recente pesquisa realizada pela Fundação Getúlio Vargas, publicada no Índice de Confiança da Justiça Brasileira - ICJ Brasil” (ARABI, 2017, p. 23).

Portanto, afora as questões de cristalização de conflitos, também no plano econômico a juridicização das condutas sociais e a recorrente judicialização dos confitos possuem suas consequências, na medida em que o crescente acionamento do Poder Judiciário exige considerável estrutura, que demanda, por sua vez, elevados custos aos cofres públicos.

\section{NECESSIDADE DE SOLUÇÕES DIALOGADAS NO ESTADO DEMOCRÁTICO DE DIREITO}

Se o Estado de Direito aponta para a limitação do poder estatal a partir das normas por ele mesmo editadas e do respeito aos direitos fundamentais, o Estado Democrático de Direito vai além, para também propiciar aos cidadãos o manejo de instrumentos adequados e viáveis para influenciar nos rumos do Estado, na condição de detentores primários e legítimos do poder.

Com efeito, na égide do Estado Democrático de Direito, deve o Estado não somente permitir ou não obstar, mas também oferecer e garantir a existência de canais dialógicos, que proporcionem aos cidadãos uma efetiva participação nos debates e decisões estatais, mediante análise crítica da realidade. Além disso, essa participação deve ser levada em consideração 


\title{
Judicialização dos conflitos sociais: reflexões sobre a necessidade de soluções dialógicas no estado democrático de direito brasileiro
}

pelos governantes na tomada das decisões, seja no acolhimento ou na rejeição, de forma fundamentada.

Vale destacar que a Constituição da República, em seu artigo $1^{\circ}$, ao alçar a cidadania à condição de fundamento da República Federativa do Brasil e prever que todo o poder emana o povo (BRASIL, 1988), imprimiu à cidadania conceito que ultrapassa a capacidade eleitoral ativa e passiva, significando que ao cidadão devem ser garantidos todos os meios adequados à participação ativa e concreta na tomada de decisões. Nesse sentido, são pertinentes as ponderações de Maria Tereza Fonseca Dias, embasadas na teoria discursiva de Jürgen Habermas:

\begin{abstract}
O princípio do discurso exige do cidadão participante uma disposição ao diálogo e à obtenção de consenso no momento de configurar sua autolegislação. Assim, o princípio da democracia só pode surgir no cerne de um sistema de direitos e de forma institucionalizada. (...) A legitimidade do direito pode ser reconhecida, na Teoria discursiva do direito e da democracia, “...através de uma compreensão procedimental do direito e de uma qualificação do cidadão que só fundamente a titularidade a direitos em relação a uma condição de cidadania que simultaneamente garanta autonomia pública e privada". A teoria do discurso, nesse sentido, opõe-se à clientelização do cidadão e o direito deve descobrir fontes de legitimação que não se encontram, atualmente, à sua disposição. Habermas (1996) descreve a necessidade de uma legitimação mais ampla do direito, que somente ocorrerá mediante a criação de canais jurídicos abertos à sociedade civil para os poderes de sancionar, organizar e executar do Estado [...]. Essa necessidade de criar canais de comunicação no âmbito da esfera pública irá desencadear alterações na forma de conceber e pensar a esfera administrativa [...], pelo emprego de um poder administrativo vinculado ao poder comunicativo [...]. (DIAS, 2003, p. 115-116)
\end{abstract}

Dessarte, por meio do diálogo deve ser possível se chegar a soluções para os conflitos sociais, mediante a construção do entendimento, em um cenário no qual os membros da sociedade não fiquem jungidos e dependentes das soluções legislativas, administrativas ou judiciais oriundas dos agentes estatais. Nesse sentido, destaca novamente Maria Tereza Fonseca Dias que:

\footnotetext{
Essa mudança de rumos na forma de perceber os "objetos" de conhecimento faz com que o direito passe a ser considerado não mais como uma realidade objetivo que nos é "dada" pelo legislador político, através do exercício parlamentar da soberania do povo e da formulação das normas jurídicas, mas sendo constituído por “....uma comunidade de interpretação cujos membros se engajam, no interior do mundo da vida intersubjetivamente compartilhado, no processo de alcançar o entendimento entre si sobre as coisas do mundo. (DIAS, 2013, p.109).
}

O caráter constitucional e democrático das soluções consensuais construídas pelos próprios atores sociais envolvidos reforça-se, ainda, a partir de uma releitura do direito de 
acesso à justiça, que não está a significar apenas a possibilidade postulatória junto aos órgãos do Poder Judiciário, com a obtenção do provimento jurisdicional. Isso porque, na lição de Lutiana Nacur Lorentz, o acesso à Justiça, “ou seja, o que os autores chamam de 'enfoque de acesso à Justiça [...], vários doutrinadores afirmam que tal movimento é, na verdade, muito mais amplo" (LORENTZ, 2002, p. 25). Não se entende, esclarece Kazuo Watanabe, como acesso à justiça, "apenas acesso formal aos órgãos judiciários, e sim acesso qualificado que propicie aos indivíduos o acesso à ordem jurídica justa" (WATANABE, 2011, p. 385). Por isso, acesso à Justiça é acesso à solução efetiva e adequada para os desentendimentos sociais, não necessariamente por meio de um provimento do Poder Judiciário, para cuja obtenção muitas vezes o interessado submete-se a níveis de tensão maiores, além de ter que arcar com o custo correspondente.

Walid Arabi, também nesse tom, após salientar que "não é só o Brasil que enfrenta o desafio da efetivação do acesso à justiça”, porque o problema se repete em outros países que “enfrentam o problema da prestação jurisdicional deficitária e, na tentativa de melhor esse quadro, propõem formas de superar as dificuldades imanentes do sistema judiciário", faz menção à Diretiva 2008/52/CE, aprovada pelo Parlamento Europeu e pelo Conselho da União Europeia, "com o objetivo de facilitar o acesso à resolução alternativa de litígios e promover a resolução amigável de litígios" (ARABI, 2017, p. 22).

Ainda nesse mesmo sentido, Bruno Gomes Borges da Fonseca pontua o seguinte:

\begin{abstract}
O paradigma do Estado democrático de direito, aliado à globalização, implica mudanças nas concepções de acesso à justiça, gerando uma verdadeira globalização dos meios acessivos, com novos instrumentos propiciantes de pacificação social. Traz presente a ideia de democratizar, seja no sentido de alargar e apresentar novos caminhos de ingresso, seja para integrar pessoas excluídas da cidadania. A economia global exige reflexão do Direito e do seu propósito de amenizar as mazelas sociais [...]. Os palcos de prevenção e resolução jurídica de conflitos devem ser repartidos dentro da estrutura estatal e, também, estendidos ao setor privado. (FONSECA, 2013, p. 60)
\end{abstract}

Assim, não se trata de substituir o Poder Judiciário, mas, sim, de acolher novas formas de composição e solução de conflitos, dada as dificuldades enfrentadas pelo Poder Judiciário, de modo a garantir efetivamente o acesso à Justiça em sua expressão material e substancial, e não meramente formal.

4 MEIOS ALTERNATIVOS DE SOLUÇÃO CONSENSUAL DOS CONFLITOS 
A Constituição da República, de 1988, em seu artigo $5^{\circ}$, inciso XXXV, estabelece que “a lei não excluirá da apreciação do Poder Judiciário lesão ou ameaça a direito" (BRASIL, 1988) do que se extrai o princípio da jurisdição, a traduzir o poder que detém o Estado de dirimir os conflitos surgidos entre as pessoas, por meio dos órgãos do Poder Judiciário.

Apesar disso, como visto, o princípio de acesso à justiça deve ser compreendido não apenas como a possibilidade de se ajuizar ações e de receber um provimento do Poder Judiciário, mas de ter solução adequada e célere para as controvérsias que naturalmente afloram no seio das relações sociais.

Os altos custos social, econômico, individual e emocional das demandas postas sob a apreciação do Poder Judiciário podem, então, ser reduzidos com a viabilização de meios alternativos de solução extrajudicial de conflitos, o que, por óbvio, traduz mais uma possibilidade posta à disposição das pessoas, sem necessariamente subtrair do Judiciário, convém repetir, o poder de dizer o direito.

A saturação do Poder Judiciário revela-se cara aos cofres públicos se se levar em conta que muitas demandas judiciais poderiam ter sido evitadas pela solução consensual e extrajudicial, de molde que somente os casos mais complexos ou que não tenham sido passíveis de conciliação pelos meios alternativos sejam efetivamente submetidos ao crivo jurisdicional.

Analisando esse fenômeno na experiência francesa, Jacques Chevallier tece algumas ponderações, cujas nuances essenciais também se aplicam ao caso brasileiro:

A saturação dos pretórios daí resultante e afetando todas as jurisdições (o número de
demandas dirigidos ao juiz administrativo passou de 22.000 em 1973 para 138.000
trinta anos mais tarde) impôs a criação de válvulas de segurança, mesmo de vias de
derivação. Paralelamente ao aperfeiçoamento dos procedimentos de urgência
existentes (ver as novas medidas cautelares administrativas introduzidas na França
pela lei de 30 de junho de 2000) e à instituição de uma justiça de proximidade
atribuída a juízes não profissionais para dispor sobre litígios de menor importância
(lei de 9 de setembro de 2002, completada pela lei orgânica de 26 de fevereiro de
2003), alguns dispositivos de filtragem do contencioso foram editados, a partir do
modelo da Comissão de Acesso aos Documentos Administrativos (CADA); quanto
aos "modelos alternativos de composição de litígios" (MARL) (mediação,
conciliação, transação...), eles adquirem uma importância crescente, inclusive no
domínio penal - as alternativas à persecução (rapel à la loi, mediação...) e os
procedimentos simplificados (ordonnances pénales e transações penais)
representando mais da metade das soluções. Todas essas medidas não poderiam ser
consideradas como um indício de um movimento de "des-judicialização"; trata-se,
ao contrário, de permitir ao aparelho judiciário funcionar, favorecendo a composição
amigável dos litígios e a simplificação das formas do processo (CHEVALLIER,
2009, p. 132-133). 
A propósito das ponderações de Chevallier, não há dúvidas de que o processo, enquanto palco propício para que os litígios submetidos ao Poder Judiciário sejam resolvidos, por meio do respeito a todas as garantias constitucionais, demanda aperfeiçoamentos que favoreçam à celeridade na prestação jurisdicional. Notadamente, cabe salientar, em razão dos longos períodos de tramitação processual, o que se deve aos exagerados formalismos, aos vários recursos disponíveis, ao crescente aumento das ações ajuizadas a cada dia, entre outros fatores, que têm como consequências a cristalização dos conflitos, a insatisfação social e muitas vezes o exercício da autotutela ilegal.

No Brasil, a Lei n ${ }^{\circ}$ 9.099, de 26 de setembro de 1995, que dispõe sobre os Juizados Especiais Cíveis e Criminais, foi criada com o objetivo de imprimir celeridade a casos de menor complexidade, regendo-se pelos princípios da oralidade, simplicidade, informalidade, economia processual e celeridade, e buscando, sempre que possível, a conciliação ou a transação ${ }^{3}$.

Não obstante, neste trabalho, a reflexão repousa na necessidade de mecanismos que permitam dirimir conflitos sem a utilização da máquina judiciária, mediante a construção da solução consensual entre as partes interessadas.

Pontue-se, por oportuno, que as soluções dialógicas, baseadas em acordos e consensos, avançam para todos os âmbitos jurídicos, sendo de se consignar, notadamente, o Direito Penal, que já conhece mecanismos de transação, acordos de leniência e acordos de colaboração premiada, que seriam inimagináveis para as tradicionais concepções penalistas. Somente a título de exemplo, cite-se a lição de Valdir Moysés Simão e Marcelo Pontes Vianna, que relacionam um conjunto de normas, internacionais e nacionais, que "fornecem aos Estados mecanismos de investigação chamados instrumentos negociais de repressão à corrupção", fazendo alusão, dentre outras, à Lei n $n^{\circ} 12.846$, de $1^{\circ}$ de agosto de 2013 ("Lei Anticorrupção"), à Lei no 12.529, de 2001 (defesa da concorrência) e Lei no 12.850, de 2013 (colaboração ou “delação" premiada) (SIMÃO; e VIANNA, 2017, p. 59-61).

Nesse panorama, serão examinados alguns meios alternativos de solução de conflitos, sendo eles: conciliação, mediação, arbitragem, termo de ajuste de conduta (TAC) e Comissões de Conciliação Prévia (CCP), a seguir abordados.

\footnotetext{
${ }^{3}$ Walid Arabi traça minucioso histórico sobre os "meios autocompositivos de solução de conflitos" previstos no ordenamento jurídico brasileiro (ARABI, 2017/26-36), mas, para os fins deste trabalho, basta a menção à Lei dos Juizados Especiais Cíveis e Criminais como documento que, mais recentemente, iniciou a busca por soluções dialógicas para os conflitos.
} 


\title{
4.1 MEDIAÇÃO E CONCILIAÇÃO
}

A mediação e a conciliação são formas pelas quais é possível alcançar a solução de conflitos sem a participação do Poder Judiciário, em que pese a possibilidade de sua utilização também no âmbito processual. Ambas as formas de solução de litígios possuem mais aspectos que as assemelham, residindo a diferença basicamente na participação mais ativa do conciliador na conciliação, em comparação com a participação do mediador na mediação, porque, nesta última, o mediador deve apenas proporcionar a construção da solução pelos próprios interessados. Nesse sentido, Fredie Didier Júnior tece os seguintes esclarecimentos acerca dos dois institutos:

\begin{abstract}
Mediação e conciliação são formas de solução de conflito pelas quais um terceiro intervém em um processo negocial, com a função de auxiliar as partes a chegar à autocomposição. Ao terceiro não cabe resolver o problema, como acontece na arbitragem: o mediador/conciliador exerce papel de catalisador da solução negocial do conflito. Não são, por isso, espécies de heterocomposição do conflito; trata-se de exemplos de autocomposição, com a participação de um terceiro. Ambas são técnicas que costumam ser apresentadas como os principais exemplos de "solução alternativa de controvérsias" (ADR, na sigla em inglês: alternative dispute resolution). $\mathrm{O}$ adjetivo, no caso, funciona para contrapor essas formas de solução dos conflitos à jurisdição estatal. Esses são os aspectos que aproximam as duas técnicas. A diferença entre a conciliação e a mediação é sutil - e talvez, em um pensamento analiticamente mais rigoroso, inexistente, ao menos em seu aspecto substancial. A doutrina costuma considerá-las como técnicas distintas para a obtenção da autocomposição. $\mathrm{O}$ conciliador tem uma participação mais ativa no processo de negociação, podendo, inclusive, sugerir soluções para o litígio. A técnica da conciliação é mais indicada para os casos e que não havia vínculo anterior entre os envolvidos. O mediador exerce um papel um tanto diverso. Cabe a ele servir como veículo de comunicação entre os interessados, um facilitador do diálogo entre eles, auxiliando-os a compreender as questões e os interesses em conflito, de modo que possam identificar, por si mesmos, soluções consensuais que gerem benefícios mútuos. (DIDIER JÚNIOR, 2015, p. 275-276)
\end{abstract}

O Novo Código de Processo Civil (Lei no 13.105, de 16 de março de 2015), em seus artigos 165 a 175, dispõe sobre a mediação e a conciliação no âmbito judicial, não excluindo, no entanto, a aplicabilidade normativa na esfera extrajudicial. Prevê, ademais, a possibilidade de aplicação das normas às câmaras privadas de conciliação e mediação.

Não se pode deixar de mencionar, por oportuno, as críticas feitas, entre outros, por Fernando Gamma de Miranda Netto e Irineu Carvalho de Oliveira Soares, de que conciliação e mediação, deturpadamente, estão sendo utilizados "simplesmente para resolver o problema estatístico do Poder Judiciário no que concerne ao extraordinário número de processos" 
(MIRANDA NETTO; e SOARES, 2016, p. 116). Também Walid Arabi, após demonstrar, com base em estatísticas do Conselho Nacional de Justiça, que os resultados da conciliação no âmbito do Poder Judiciário tem sido frustrantes (ARABI, 2017, p. 79), salienta que os "milhares de procedimentos de mediação [...] levados aos Centros Judiciários de Solução de Conflitos", possam não produzir o resultado imaginado, ensejando "dúvidas e questionamentos a respeito da eficiência da mediação judicial até mesmo por aqueles que conhecem e vivenciam a realidade dos nossos tribunais" (ARABI, 2017, p. 80).

Portanto, conciliação e mediação não são panaceia, sendo, sim, instrumentos valiosos, cuja utilidade e eficiência dependerá, inegavelmente, do bom uso que deles se faça.

\title{
4.2 ARBITRAGEM
}

Carlos Alberto Carmona conceitua a arbitragem como:

\begin{abstract}
Meio alternativo de solução de controvérsias através da intervenção de uma ou mais pessoas que recebem seus poderes de uma convenção privada, decidindo com base nela, sem intervenção estatal, sendo a decisão destinada a assumir a mesma eficácia da sentença judicial - é colocada à disposição de quem quer que seja, para solução de conflitos relativos a direitos patrimoniais acerca dos quais os litigantes possam dispor. (CARMONA, 1998, p. 44)
\end{abstract}

A arbitragem funda-se na autonomia da vontade privada, mediante a qual os interessados capazes, via cláusula compromissária ou convenção de arbitragem, conferem ao um terceiro (árbitro) o poder de decidir a respeito da questão, substituindo ao juiz que atua no processo judicial.

A Lei $\mathrm{n}^{\circ}$ 9.307, de 23 de setembro de 1996, dispõe sobre a arbitragem o Brasil, com a previsão de todo o regramento aplicável ao instituto. As dificuldades enfrentadas pela arbitragem, em certa medida, decorrem da cultura da judicialização, mas a alteração produzida Lei $\mathrm{n}^{\mathrm{o}}$ 13.129, de 2015, que estendeu o uso da arbitragem também para a administração pública direta e indireta, em relação aos "conflitos relativos a direitos patrimoniais disponíveis" ( $\S 1^{\circ}$ do art. $1^{\circ}$ da Lei $n^{\circ} 9.307$, de 1996 , na redação dada pela Lei $n^{\circ}$ 13.129, de 2015), tende a potencializar o uso da arbitragem.

Cite-se que há a tradicional vinculação entre a arbitragem e as relações empresariais (CARMONA, 1998), não sendo o melhor instrumento para pacificar relações sociais. 
Não obstante, trata-se de meio posto pela legislação à disposição dos interessados, fundado na autonomia da vontade privada e na busca de solução extrajudicial mais célere.

\subsection{TERMO DE AJUSTE DE CONDUTA}

O Termo de Ajuste de Conduta (TAC), regulado pelo $\S 6^{\circ}$ do artigo $5^{\circ}$ da Lei $n^{\circ} 7.347$, de 1985 (Lei de Ação Civil Pública) ${ }^{4}$, na dicção de Raimundo Simão de Melo, "tem sua origem no art. 55, parágrafo único da Lei n. 7.244/84 - Lei das Pequenas Causas - que conferiu ao acordo extrajudicial celebrado entre as partes e referendado pelo Ministério Público natureza de título executivo extrajudicial” (MELO, 2008, p. 68).

No que tange à natureza jurídica, segundo previsto no $\$ 6^{\circ}$ do $\operatorname{artigo} 5^{\circ}$, da Lei $n^{\circ}$ 7.347/1985, o TAC é considerado título executivo extrajudicial, mas resulta do diálogo e livre decisão das partes interessadas, pode ser considerado um negócio jurídico transacional que se consubstancia no título executivo extrajudicial. Envolve o interessado, que pode ser pessoa física ou jurídica, e o poder público, representado pelos agentes legitimados à propositura da ação civil pública, no qual são pactuadas obrigações de fazer, de não fazer, de pagar e/ou de dar, como forma de prevenir litígios judiciais e garantir o respeito a direitos difusos, coletivos ou individuais homogêneos.

Como salientam Rogério Bastos Arantes, Maria Rita Loureiro, Cláudio Couto e Marco Antonio Carvalho Teixeira, que examinam a questão sob o enfoque da Ciência Política, o "TAC tem a vantagem de produzir efeitos práticos sem que seja necessária a intervenção do Judiciário" (ARANTES; LOUREIRO; COUTO; TEIXEIRA, 2014, p. 140). Apontam os referidos autores a preferência do Ministério Público, em seus vários ramos, pela adoção do TAC, porque, "em tese, ganham-se tempo e efetividade [...] diante da morosidade da Justiça e da dificuldade de obter respostas judiciais eficazes" (ARANTES; LOUREIRO; COUTO; TEIXEIRA, 2014, p. 140), salientando que "a adoção de um TAC entre MP e administradores tem o efeito de impor custos reputacionais a esses últimos e de apressar a solução concreta dos casos" (ARANTES; LOUREIRO; COUTO; TEIXEIRA, 2014, p.140).

Em termos de efetivação de direitos sociais, a atuação do Ministério Público se mostra essencial e a utilização do TAC permite buscar soluções mais eficientes para a efetivação de

\footnotetext{
${ }^{4}$ Lei no 7.347 , de 1985: "Art. $5^{\text {o }}$ Têm legitimidade para propor a ação principal e a ação cautelar: [...] $\S 6^{\circ}$ Os órgãos públicos legitimados poderão tomar dos interessados compromisso de ajustamento de sua conduta às exigências legais, mediante cominações, que terá eficácia de título executivo extrajudicial”.
} 
tais direitos sociais. E o fato de a solução não decorrer de uma decisão judicial, certamente, não compromete a lisura do ajuste celebrado, havendo inegáveis ganhos de eficiência por se tratar de solução acordada diretamente entre os envolvidos e o Ministério Público, sem as delongas peculiares ao processo judicial. De resto, tratando-se de título executivo extrajudicial, eventuais litígios decorrentes do TAC encontrarão resolução no âmbito judiciário, partindo-se, porém, de um procedimento teoricamente mais célere, qual seja, a execução, no qual a parte envolvida poderá exercer amplo direito de defesa.

\subsection{COMISSÕES DE CONCILIAÇÃO PRÉVIA}

O artigo 625-A, da Consolidação das Leis do Trabalho (CLT), introduzido pela Lei $\mathrm{n}^{\circ}$ 9.958/2000, estabelece a possibilidade de empresas e sindicato instituírem Comissões de Conciliação Prévia, de composição paritária, constituídas por representantes dos empregados e dos empregadores, destinadas a tentar conciliar conflitos de natureza individual do trabalho, com ênfase, assim, para uma construção dialógica entre as partes envolvidas.

De acordo com o artigo 625-E, da CLT, sendo alcançado acordo alcançado por meio da atuação das Comissões de Conciliação Prévia, será lavrado termo, assinado pelo empregado, pelo empregador ou seu preposto e pelos membros da Comissão, revestindo-se esse termo de natureza jurídica de título executivo extrajudicial, com eficácia liberatória geral, exceto no que tange às parcelas expressamente ressalvadas, nos termos do parágrafo único do referido artigo.

Por meio das Comissões de Conciliação Prévia tenta-se alcançar solução consensual, sem subtrair ou condicionar o recurso ao Poder Judiciário, forte no princípio da inafastabilidade da jurisdição. Também aqui, contudo, a cultura da judicialização resulta em certo desprestígio dessas Comissões, que podem se tornar, contudo, meios mais eficazes para a efetivação dos direitos sociais.

\section{VANTAGENS DOS MEIOS ALTERNATIVOS DE SOLUÇÃO DE LITÍGIOS}

A principal vantagem proporcionada pelos meios alternativos ou adequados é permitir aos próprios interessados a construção das soluções para os seus conflitos, o que está a 
apontar para um considerável incremento no nível de maturidade democrática e civilizatória de uma sociedade.

Mesmo em relação à arbitragem, em que um terceiro decide, não se pode subtrair esse viés democrático, na medida em que o árbitro pode ser escolhido pelos próprios interessados, com a possibilidade de que essa escolha recaia sobre pessoa mais apta para "julgar" a causa, com conhecimentos técnicos específicos para o caso concreto, o que, muitas vezes, não ocorre em relação aos órgãos do Poder Judiciário.

Uma vez que os próprios interessados participam ativamente na construção da solução, tem-se também a amenização dos níveis de tensão e uma maior possibilidade de que a decisão final seja acatada e cumprida, logrando-se efetividade na concretização da pacificação social.

Ademais, podem ser citados os baixos custos dos meios alternativos se comparados com aqueles envolvidos nas ações judiciais, maior celeridade na solução dos casos e a diminuição dos acervos processuais cada vez maiores no Poder Judiciário, que poderá, assim, se ocupar com aquelas demandas que de fato reclamem o seu pronunciamento.

Há que se pontuar, contudo, que todos esses meios ainda encontram forte resistência a partir do que se denominou, ao longo deste trabalho, de cultura da judicialização, em uma crença disseminada na sociedade de que apenas o Estado-Juiz pode oferecer a justa solução para os litígios. Essa crença, porém, não corresponde à realidade brasileira (e se poderia dizer mundial), sendo importante insistir na divulgação e implantação de meios alternativos de litígios, também no que concerne aos direitos sociais, sempre com as precauções devidas, é claro.

\section{CONCLUSÃO}

A previsão de direitos sociais representa importante e histórica conquista contra os abusos estatais. No entanto, a inflação legislativa, consequência da sacralização do direito e da juridicização das relações sociais, e o aumento cada vez maior das demandas judiciais representam elevado custo econômico e social para o Estado, além de cristalizar cada vez mais os conflitos que naturalmente afloram em qualquer sociedade.

A concretização do Estado Democrático de Direito exige que se proporcionem aos próprios interessados os mecanismos que permitam e viabilizem a construção de soluções consensuais por eles próprios, sem a necessidade recorrente de se demandar perante o Poder Judiciário. 
A mediação, a conciliação, a arbitragem, o termo de ajuste de conduta e as comissões de conciliação prévia podem ser considerados importantes mecanismos para o alcance de soluções consensuais e extrajudiciais. Não obstante possam ser citados os baixos custos, os menores níveis de tensão social, a celeridade, a eficiência e a eficácia, tem-se que a principal vantagem proporcionada pelos meios alternativos reside em permitir aos próprios interessados a construção das soluções para os seus conflitos, o que está a apontar para um considerável incremento no nível de maturidade democrática e civilizatória de uma sociedade.

A efetiva utilização desses meios, porém, ainda exige a superação de certa cultura da judicialização, superando-se a crença de que apenas o Poder Judiciário poderia, pela via do litígio processual, resolver adequadamente os conflitos sociais e implementar os direitos sociais.

\section{REFERÊNCIAS BIBLIOGRÁFICAS}

ARABI, Walid Machado Botelho. A institucionalização da mediação no direito brasileiro. 2017. 98f. Dissertação (Mestrado). Universidade FUMEC, Belo Horizonte.

ARANTES, Rogério Bastos; LOUREIRO, Maria Rita; COUTO, Cláudio; e TEIXEIRA, Marco Antônio Carvalho. Controles democráticos sobre a administração pública no Brasil: Legislativo, tribunais de contas, Judiciário e Ministério Público. In: Burocracia e política no Brasil - Desafios para a ordem democrática no século XXI. LOUREIRO, Maria Rita; ABRUCIO, Fernando Luiz; e PACHECO, Regina Silva. 1 ed. - 3 reimpressão. Rio de Janeiro: Editora FGV, 2014, p. 109-147.

BONAVIDES, Paulo. Curso de direito constitucional. 25 ed. São Paulo: Malheiros, 2010.

BRASIL. Constituição da República Federativa do Brasil (1988). Disponível em: <http://www.planalto.gov.br/ccivil_03/constituicao/ConstituicaoCompilado.htm>. Acesso em: 30 abr.2017.

BRASIL. Conselho Nacional de Justiça. Relatório Justiça em números. Ano-base 2015, $2016 . \quad$ Disponível em: <http://cnj.jus.br/files/conteudo/arquivo/2016/10/b8f46be3dbbff344931a933579915488.pdf> Acesso em: 08 jan.2017.

BRASIL. Decreto-lei $n^{0}$ 5.452, de $1^{\circ}$ de maio de 1943. Consolidação das Leis do Trabalho. Disponível em: <https://www.planalto.gov.br/ccivil_03/Decreto-Lei/Del5452compilado.htm> Acesso: em 30 abr.2017.

BRASIL. Lei Federal no 7.347, de 24 de julho de 1985. Lei da Ação Civil Pública. Disponível em: <https://www.planalto.gov.br/ccivil_03/LEIS/L7347Compilada.htm>. Acesso em: 30 abr.2017. 
BRASIL. Lei Federal $\mathbf{n}^{\mathbf{0}} \mathbf{9 . 0 9 9}$, de 26 de setembro de 1995. Disponível em: <http://www.planalto.gov.br/ccivil_03/leis/L9099.htm> Acesso em 30 abr.2017.

BRASIL. Lei Federal $\mathbf{n}^{0}$ 9.307, de 23 de setembro de 1996. Lei da Arbitragem. Disponível em: <http://www.planalto.gov.br/ccivil_03/LEIS/L9307.htm> . Acesso em 30 abr.2017.

BRASIL. Lei Federal $\mathbf{n}^{\mathbf{0}}$ 13.105, de 16 de março de 2015. Código de Processo Civil. Disponível em: <http://www.planalto.gov.br/ccivil_03/_ato2015-2018/2015/lei/113105.htm> Acesso em: 30 abr.2017.

BRASIL. Lei Federal $\mathbf{n}^{0}$ 13.140, de 26 de junho de 2015. Lei da Mediação. Disponível em: < http://www.planalto.gov.br/ccivil_03/_ato2015-2018/2015/Lei/L13140.htm> Acesso em 30 abr.2017.

CARMONA, Carlos Alberto. Arbitragem e processo: um comentario à Lei 9.307/96. São Paulo: Malheiros, 1998.

CHEVAlliER, Jacques. O estado de direito. Tradução de Antonio Araldo Ferraz Dal Pozzo, Augusto Neves Dal Posso. Belo Horizonte: Fórum, 2013.

CHEVALLIER, Jacques. O estado pós-moderno. Tradução de Marçal Justen Filho. Belo Horizonte: Fórum, 2009.

DIAS, Maria Tereza Fonseca. Direito administrativo pós-moderno. Belo Horizonte: Mandamentos, 2003.

DIDIER JÚNIOR, Fredie. Curso de direito procesual civil. Introdução ao direito processual civil, parte geral e proceso de conhecimento. 17.ed. Salvador: Editora Jus Podivm, 2015, v. 1.

DOUZINAS, Costas. O fim dos direitos humanos. Tradução de Luzia Araújo. São Leopoldo: Unisinos, 2009.

FONSECA, Bruno Gomes Borges da. Compromisso de ajustamento de conduta. São Paulo: Ltr, 2013.

GUERRA, Sidney. Direitos humanos: curso elementar. 3.ed. São Paulo: Saraiva, 2015.

LENZA, Pedro. Direito constitucional esquematizado. 18.ed. São Paulo: Saraiva, 2014.

LORENTZ, Lutiana Nacur. Métodos extrajudiciais de solução de conflitos trabalhistas. São Paulo: Ltr, 2002.

MELO, Raimundo Simão de. Ação civil pública na justiça do trabalho. 3.ed. São Paulo: Ltr, 2008.

RÓNAI, Paulo. Dicionário universal Nova Fronteira de citações. 3. ed. Rio de Janeiro: Nova Fronteira, 1986. 
SANTOS, Boaventura de Sousa. Introdução à sociologia da adminstração da justiça. In: Revista crítica de ciências sociais. Coimbra, $\mathrm{n}^{\circ}$ 21, novembro, 1986, p. 11-44. Disponível http://www.boaventuradesousasantos.pt/media/pdfs/Introducao_a_sociologia_da_adm_justica -RCCS21.PDF>. Acesso em: 08 maio.2017.

SIMÃO, Valdir Moysés; e VIANNA, Marcelo Pontes. O acordo de leniência na lei anticorrupção - histórico, desafíos e perspectivas. São Paulo: Trevisan Editora, 2017.

WATANABE, Kazuo. Política pública do Poder Judiciário nacional para tratamento adequado dos conflitos de interesse. In: Revista de Processo. São Paulo: Revista dos Tribunais, v. 195, 2011, p. 381-390. 